\title{
Synergistic effects of an oil dispersant and low temperature on the freezing tolerance and solute concentrations of the blue mussel (Mytilus edulis L.)
}

\author{
ARNE VOLLAN AARSET AND KARL ERIK ZACHARIASSEN
}

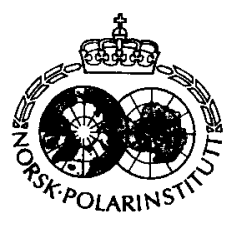

\begin{abstract}
Aarset, A. V. \& Zachariassen, K. E. 1983: Synergistic effects of an oil dispersant and low temperature on the freezing tolerance and solute concentrations of the blue mussel (Mytilus edulis L). Polar Research 1 n.s., 223-229.

Exposure of blue mussels (Mytilus edulis L.) to an oil dispersant in increasing concentrations caused increased degree of injury in the mussels. The oil dispersant seemed to affect mechanisms responsible for the distribution of inorganic ions $\left(\mathrm{Na}^{+}, \mathrm{K}^{+}, \mathrm{Cl}^{-}\right)$and free amino acids across the cell membranes. The dispersant caused a marked reduction in the ability of the mussels to survive freezing at $-10^{\circ} \mathrm{C}$. Freezing also caused more pronounced alterations in the transmembrane ionic distributions observed following exposure to the dispersant. This may indicate that the injuries caused by freezing are qualitatively the same as those caused by exposure to the dispersant alone, but brought into more extreme conditions. Thus, freezing appears to potentiate the effect of environmental pollutions by concentrating them in the fluid fraction of the frozen body fluids.
\end{abstract}

Arne Vollan Aarset and Karl Erik Zachariassen, Department of Zoology, University of Trondheim, 7055 Draguoll, Norway.

\section{Introduction}

In many oil spills detergents or emulsifiers have been used to help disperse the oil. Several studies have shown that the dispersing agents may cause more damage to living organisms than the oil itself (George 1961; Nelson-Smith 1968; Odum et al. 1974). Little is known, however, about the effects of oil dispersants on the abilities of littoral organisms to tolerate variations of natural ecological parameters such as temperature.

In the North Atlantic region sessile littoral molluscs like the blue mussel Mytilus edulis are frequently exposed to air temperatures down to $-20^{\circ} \mathrm{C}$ at low tide in winter (Kanwisher 1955). As demonstrated by Kanwisher (1955), cold exposure during low tide will be accompanied by freezing of the extracellular body fluid of Mytilus. The ability of the blue mussel to tolerate low temperatures in a frozen state is correlated with the salinity to which the mussels are acclimated, so that the cold-hardiness increases with increasing salinities (Williams 1970). Lange (1963) showed that acclimation to high salinities is accompanied by increases in the intracellular concentrations of free amino acids and other ninhydrin positive substances, which constitute up to about $50 \%$ of the intracellular solutes of
Mytilus. Williams (1970) suggested that the intracellular amino acids might have a cryoprotective effect in these bivalves, and that this may be the basis of the high cold-hardiness of mussels acclimated to high salinities.

The purpose of the present study has been to investigate to what extent an oil dispersant in sublethal concentrations alters the concentrations of inorganic ions and free amino acids in Mytilus edulis and the ability of the mussels to tolerate cold-exposure at low tide in winter. The study has been carried out in the laboratory by exposing $M$. edulis to sea water mixed with the dispersant and observing the effect on their cold-hardiness and the concentrations of free amino acids and inorganic ions in the body fluid compartments by comparison with the corresponding values of a control group kept in unpolluted sea water.

\section{Materials and methods}

Specimens of Mytilus edulis L. (length $5-7 \mathrm{~cm}$ ) were collected in the intertidal zone in Verrafjorden, county of Sør-Trøndelag, Norway, in October 1981. The animals were transported within thermos bottles to the laboratory, where they were acclimated for $3-4$ weeks at $5-6^{\circ} \mathrm{C}$ to 
a salinity of $30 \% c$ using an aquarium system with recirculating sea water. The sea water was aerated and filtered through an Eheim filter unit consisting of two mechanical filters with different pore sizes and an adsorptive charcoal filter. The sea water flow was maintained at approximately $3.0 \mathrm{l} / \mathrm{min}$. The animals were not fed during the experiment.

\section{Acute toxicity test}

Groups of animals, each of nine mussels, were transferred from the acclimation bath to baths containing different concentrations of the oil dispersant Finasol OSR-5, kept in aerated glass aquaria. The oil dispersant was dissolved in $30 \%$ c sea water at $5-6^{\circ} \mathrm{C}$, and dispersant concentrations of 50,100, 300, 500, and $1000 \mathrm{ppm}$ were used to determine the toxicity (EC 50). The experiment lasted for $150 \mathrm{~h}$ and the effects were continuously recorded during the test. A control group of mussels were kept in unpolluted sea water $(30 \%)$ at the same temperature. The experimental media were changed every day. Two parallel experimental series were run.

One problem in using adult mussels in toxicity studies is the tendency of the animals to close their shells when stimulated by an obnoxious substance (Simpson 1968; Crapp 1971). To ensure that the mussels were exposed to the experimental medium, the mantle cavities were flushed and refilled with the surrounding medium at the beginning of each experiment.

The effects of exposure to the dispersant were quantified according to behavioural criteria. When a normal submersed mussel is touched, it will respond by contracting its adductor muscles and closing the valves (Swedmark et al. 1971; Lee et al. 1972; Fossato \& Canzonier 1976). The loss of ability to close the valves when the clams were touched by a glass rod was used in the present study as 'injury' criterion. The shells were also classified as 'injured' if the shell opening remained wider than about $1 \mathrm{~mm}$ after a closing response. Mussels that did not show any degree of injury after the toxicity test were selected for the freezing experiments.

\section{Freezing experiments}

Under natural conditions the mantle cavity is filled with sea water during freezing (Williams 1970 ); similar conditions were used in the present experiments. To accomplish this the shells were kept permanently closed by means of rubber strings when removed from the experimental medium. The mussels were transferred to airfilled PVC-bottles, which were immersed in an ethanol/water cooling bath. The bath temperature could be regulated within $\pm 0.05^{\circ} \mathrm{C}$. The animals were exposed to $-10^{\circ} \mathrm{C}$ for $12 \mathrm{~h}$; the mussels were then taken out of the bottles and transferred back to their respective experimental media. The mussels were observed every hour to ascertain the effect of the freezing.

\section{Samples of haemolymph and tissue}

Samples of haemolymph $(0.5-1 \mathrm{ml})$ were taken by means of a syringe from the pallial sinus (Bayne et al. 1976). The haemolymph was centrifuged and the supernatant stored at $-25^{\circ} \mathrm{C}$. The posterior adductor muscle was then dissected out and cut in three parts for analysis of intracellular free amino acids, inorganic ions and relative water content.

\section{Amino acids}

The concentrations of free amino acids in muscle tissue (mmole $/ \mathrm{kg}$ tissue water) and haemolymph (mmoles/kg plasma) were determined as taurin equivalents of free ninhydrin positive substances (NPS) according to a method described by Moore \& Stein $(1948,1954)$.

\section{Osmolality}

The osmolality of the body fluids was determined by measuring the melting point of $50 \mu \mathrm{l}$ samples of haemolymph on a Knauer osmometer.

\section{Inorganic ions}

The concentration of chloride was determined by using a radiometer chloride titrator. The chloride concentrations in haemolymph were determined directly with the samples of haemolymph, whereas the chloride concentration in muscle tissue was determined after acid extraction in $\mathrm{HNO}_{3}$ of pre-weighed tissue fragments (Whittam 1955; Little 1964: Lutz 1972; Aarset \& Zachariassen 1982).

The content of cations was determined on a Perkin Elmer 303 atomic absorbtion spectrophotometer. The contents of $\mathrm{Na}^{+}$and $\mathrm{K}^{+}$in the haemolymph were determined after dilution with 
deionized water in order to make use of the optimum range of the spectrophotometer. The concentrations of monovalent ions in muscle tissues were determined on the same tissue fragments as those used for the chloride determinations. Standard solutions were prepared according to the Perkin Elmer manual.

To obtain correct values for the intracellular concentrations in muscle tissue, the values were corrected for ions present in the extracellular tissue fluid. According to Williams (1970), the extracellular space of the posterior adductor muscle of Mytilus amounts to about $10 \%$ of the total muscle tissue fluid, and this value was used for the corrections in the present study.

\section{Relative water content of muscle tissue}

The relative water content of the muscle tissue was determined by drying pre-weighed muscle fragments to constant weight at $+105^{\circ} \mathrm{C}$.

\section{Results}

\section{Acute toxicity tests and freezing tolerance}

Table 1 summarizes the effects of the oil dispersant (Finasol OSR-5) on the ability of the mussel Mytilus edulis to close the shells before and after exposure to $-10^{\circ} \mathrm{C}$. The $150 \mathrm{~h}$-median effective concentration (EC50) as calculated by probit analysis (Finney 1971) is about four times higher than the EC50-value obtained after $1 \mathrm{~h}$ recovery following the freezing stress. During recovery of the mussels the EC50 value increases and is $100 \mathrm{ppm}$ higher after a recovery period of $3 \mathrm{~h}$. A period of $3 \mathrm{~h}$ was used because this seems to be sufficient for unpolluted mussels to recover (Aarset \& Zachariassen 1982). This demonstrates that mussels exposed to subfreezing temperatures after pollution are significantly more sensitive to the pollutant than unfrozen mussels.

Table 1. Concentrations (EC-50) of an oil dispersant (Finasol OSR-5) affecting shell closure of the mussel $M$. edulis before and after a freezing stress.

\begin{tabular}{|c|c|c|c|}
\hline \multirow{2}{*}{$\begin{array}{l}\text { Acute toxicity test } \\
150 \mathrm{~h}\end{array}$} & \multicolumn{3}{|c|}{$\begin{array}{l}\text { Recovery time after } 12 \mathrm{~h} \\
\text { freezing at }-10^{\circ} \mathrm{C}\end{array}$} \\
\hline & $1 \mathrm{~h}$ & $2 \mathrm{~h}$ & $3 \mathrm{~h}$ \\
\hline $795 \mathrm{ppm}$ & $200 \mathrm{ppm}$ & 234 ppm & $300 \mathrm{ppm}$ \\
\hline
\end{tabular}

\section{Inorganic ions and osmolality}

Figure 1 shows the concentrations of inorganic ions and the osmolality in haemolymph of frozen and unfrozen specimens of $M$. edulis exposed to various concentrations of the dispersant. There were no significant changes in haemolymph osmolality (Fig. 1a) at any of the concentrations of the dispersant (Student's t-test).

Figure $1 \mathrm{~b}$ shows that haemolymph concentrations of $\mathrm{Na}^{+}$decrease significantly with increasing concentrations of the dispersant, except for unfrozen mussels exposed to $500 \mathrm{ppm}$. There was also a significant difference in $\mathrm{Na}^{+}$concentrations between frozen and unfrozen mussels at 300 and $500 \mathrm{ppm}$, with the lowest values in the haemolymph of the frozen animals.

Figure 1c shows that haemolymph concentrations of potassium do not change significantly in any of the mussels, but the values are somewhat fluctuating in most of the experimental groups.

Figure 1d shows that haemolymph concentrations of chloride are significantly lower in mussels exposed to $1000 \mathrm{ppm}$ dispersant than in unpolluted mussels.

Figure 2 shows the concentrations of inorganic ions in the posterior adductor muscle of frozen and unfrozen mussels exposed to various concentrations of the dispersant. Separate plots are given for the ionic concentrations of injured specimens (frozen and unfrozen) and those that appear to be unaffected by the pollution.

Figure 2a shows that concentrations of $\mathrm{Na}^{+}$ increase significantly with increasing concentrations of the dispersant. There was also a significant difference in $\mathrm{Na}^{+}$concentrations between frozen and unfrozen mussels at the two highest concentrations of the dispersant, frozen mussels having the highest values. The concentrations of $\mathrm{Na}^{+}$in the muscles of injured animals (Fig. 2a) are markedly elevated compared to the concentrations in normally behaving mussels, which seem to be rather constant and not significantly different from those of unpolluted mussels.

Figure $2 \mathrm{~b}$ shows that the intracellular concentrations of potassium decrease significantly with increasing concentrations of the dispersant. There was also a significant difference in $\mathrm{K}^{+}$concentrations between frozen and unfrozen animals at the two highest concentrations of the dispersant, the lowest values being found in the frozen mussels.

The concentrations of $\mathrm{K}^{+}$in the muscles of injured animals are significantly lower than corresponding concentrations in normally behaving 


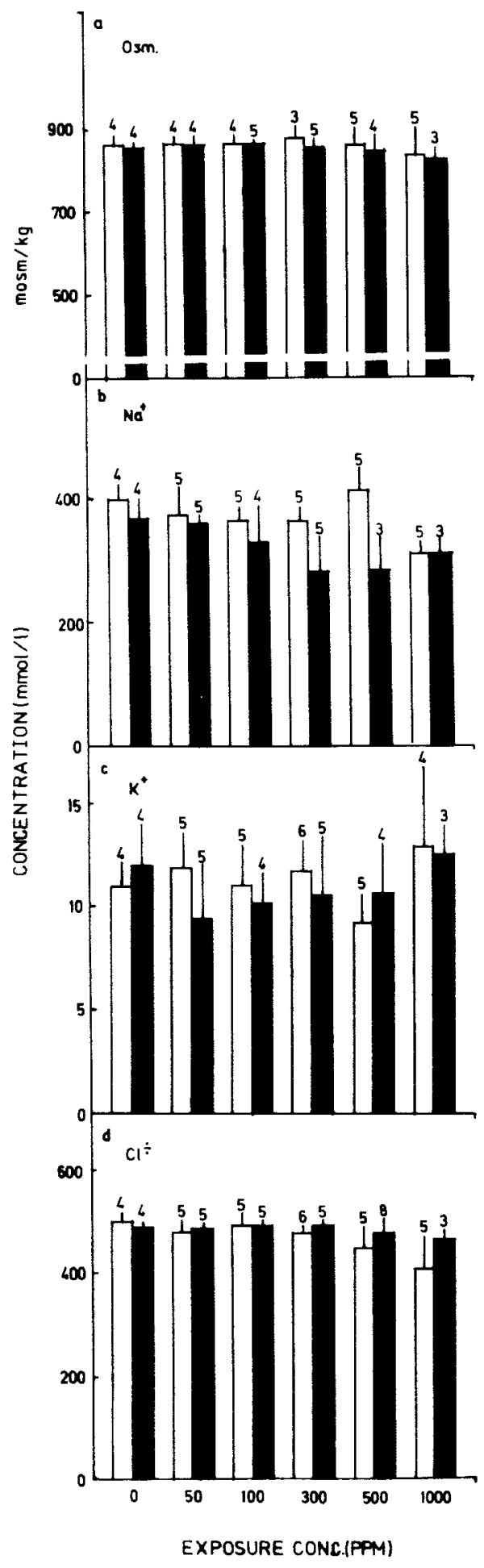

Fig. 1. Concentrations of inorganic ions and osmolality in the haemolymph of frozen $\left(-10^{\circ} \mathrm{C}\right)$ and unfrozen $\left(+5^{\circ} \mathrm{C} \square\right)$ specimens of $M$. edulis exposed to various concentrations of the dispersant.

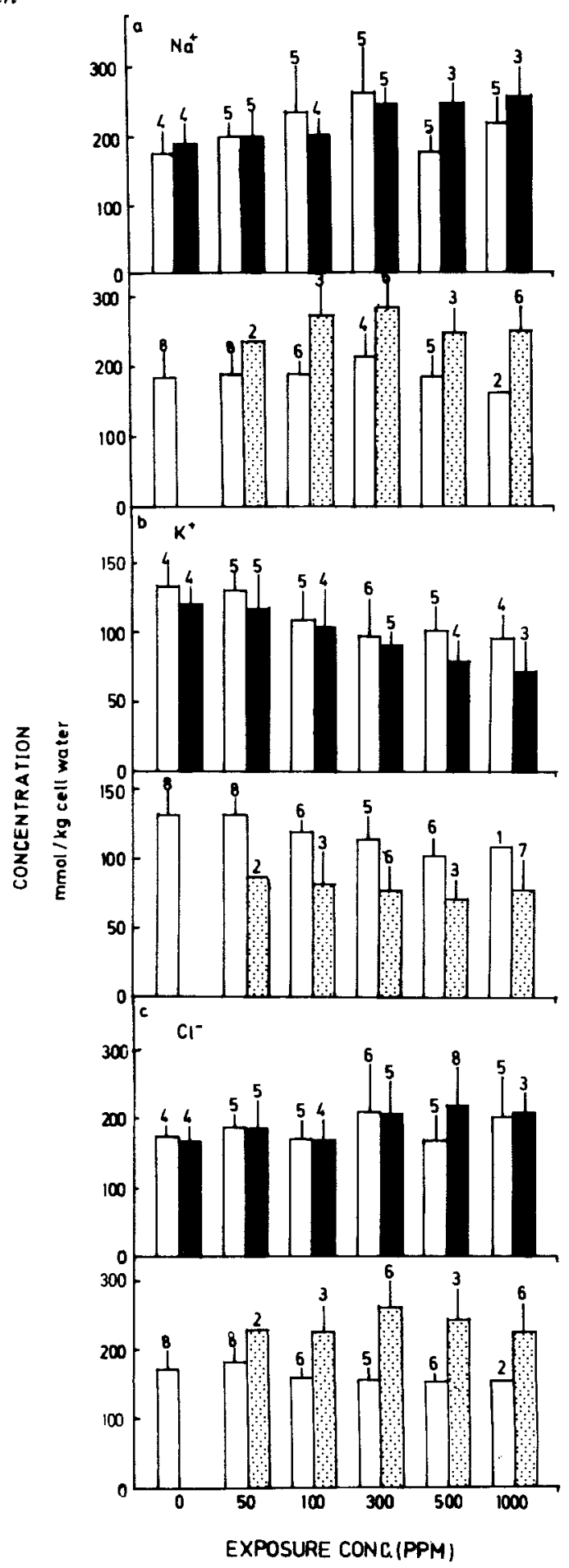

Fig. 2. Concentrations of inorganic ions in the posterior adductor muscle of frozen $\left(-10^{\circ} \mathrm{C}\right)$ and unfrozen $\left(+5^{\circ} \mathrm{C} \square\right)$ specimens of $M$. edulis exposed to various concentrations of the dispersant. Separate plots are given for injured (国) and unaffected $(\square)$ mussels. The standard deviation and the numbers of individuals are indicated on the top of each bar. 
mussels. In these mussels, however, the $\mathrm{K}^{+}$-concentrations decreased significantly with increasing concentrations of the dispersant.

Figure $2 c$ shows that the intracellular concentrations of chloride in the posterior adductor muscle increase significantly with increasing concentrations of the dispersant. There are no significant differences in chloride concentration between frozen and unfrozen animals, except for the mussels exposed to $500 \mathrm{ppm}$ Finasol OSR-5.

The concentrations of chloride in the muscles of injured animals are significantly higher than the corresponding concentrations in normally behaving mussels. The chloride concentrations in the muscles of the latter animals were quite constant and not significantly different from those of unpolluted animals.

\section{Free amino acids (NPS)}

Figure 3 shows the concentrations of free amino acids (NPS) in the posterior adductor muscle and

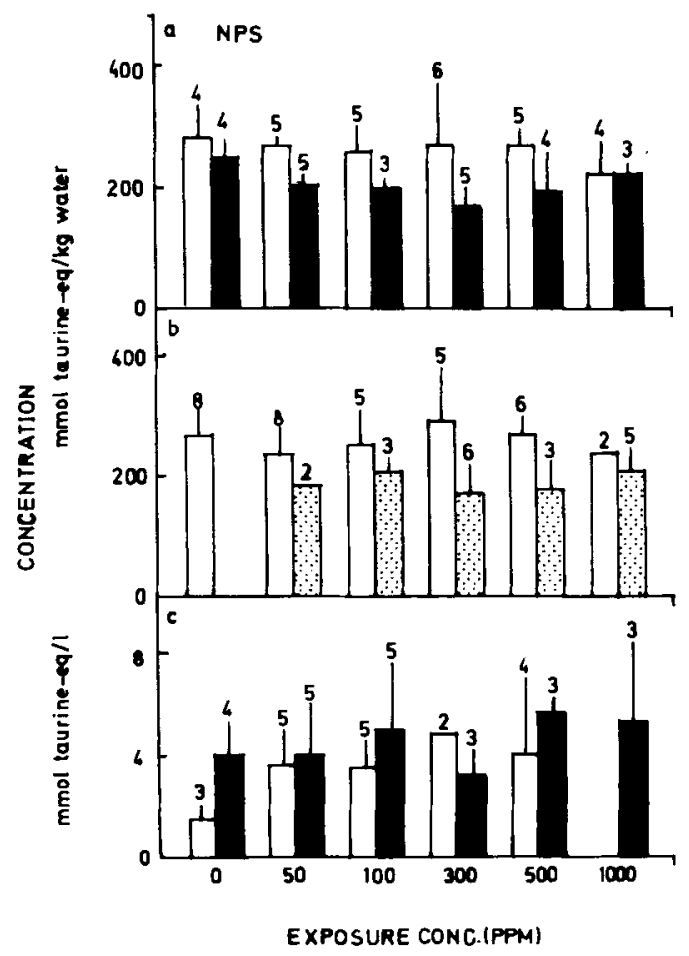

Fig. 3. Concentrations of free amino acids (NPS) in the posterior adductor muscle and the haemolymph of frozen $\left(-10^{\circ} \mathrm{C}\right)$ and unfrozen $\left(+5^{\circ} \mathrm{C} \square\right)$ specimens of $M$. edulis exposed to various concentrations of the dispersant. Separate plots are given for injured (圈) and unaffected ( $\square$ ) mussels. the haemolymph of frozen and unfrozen mussels exposed to various concentrations of the dispersant. The concentrations of injured (frozen and unfrozen) and uninjured (frozen and unfrozen) animals are plotted separately.

Figure $3 \mathrm{a}$ shows that the intracellular concentrations of free amino acids in the muscle of unfrozen animals exposed to $1000 \mathrm{ppm}$ dispersant are significantly lower than those of unpolluted animals.

There were also significantly lower NPS concentrations in frozen than in unfrozen mussels. Exceptions were the concentrations of animals exposed to the highest concentrations of the dispersant.

Animals classified as injured have significantly lower intracellular concentrations of free amino acids at all but the highest concentrations of the dispersant, where no difference could be found.

Figure $3 \mathrm{~b}$ shows that the concentrations of free amino acids in the haemolymph of unfrozen animals are significantly higher in polluted mussels, whereas no significant difference seems to exist between mussels in the various concentrations of the dispersant. Frozen mussels exposed to 0 and $100 \mathrm{ppm}$ have significantly higher concentrations of amino acids than unfrozen animals. There were no significant differences between the NPS levels in any of the other groups.

\section{Discussion}

The present results indicate that exposure to oil dispersant in increasing concentrations causes increasing degrees of injury in Mytilus edulis mussels. It is also evident that the dispersant affects mechanisms responsible for the distribution of inorganic ions and free amino acids across the cell membranes.

The observed drop in haemolymph $\mathrm{Na}^{+}$concentration and increase in intracellular $\mathrm{Na}^{+}$concentration indicate that the dispersant affects either the cell membrane permeability to $\mathrm{Na}^{+}$, the active transport system to $\mathrm{Na}^{+}$across the cell membranes, or the metabolic processes supplying energy to the active $\mathrm{Na}^{+}$pump system. If there were an effect on the transmembrane permeability, it would probably also take place in the membranes separating the haemolymph from the mantle fluid and cause a flux of $\mathrm{Na}^{+}$from the mantle fluid to the haemolymph, compensating the loss of $\mathrm{Na}^{+}$to the intracellular compartments. 
The observed drop in haemolymph $\mathrm{Na}^{+}$concentration indicates that no such compensatory flux has taken place; the possibility of an effect on the membrane permeability appears unlikely therefore. The present results allow no conclusion to be drawn as to whether there is a direct effect on the transport system or an indirect effect by inhibition of metabolism.

A change in the distribution of an actively transported ion like $\mathrm{Na}^{+}$across the cell membranes is also likely to alter the distribution of charged solutes like $\mathrm{K}^{+}$and $\mathrm{Cl}^{-}$, by means of a Gibbs Donnan effect. This is likely to be the basis of the transmembrane distribution of $\mathrm{K}^{+}$and $\mathrm{Cl}^{-}$, which in the present study is observed to take place concomitantly with the change in the distribution of $\mathrm{Na}^{+}$.

A reduced transmembrane electrochemical potential difference of $\mathrm{Na}^{+}$across the cell membranes is likely to reduce the ability of the mussels to accumulate free amino acids in the intracellular compartments. in that this accumulation to a great extent is assumed to depend on a $\mathrm{Na}^{+}$dependent transport system (Pequignat 1973). The present study reveals no significant drop in the intracellular concentration of free amino acids, except at the highest concentration of the dispersant, but the significant increase in the concentration of free amino acids in the haemolymph reveals that the transmembrane distribution of free amino acids is affected. It should here be kept in mind that because of the comparatively high concentration of free amino acids in the intracellular compartments in relation to those in the haemolymph, even a very moderate reduction of the intracellular concentration may give rise to a marked increase in the concentration in the haemolymph.

The present results reveal that an increasing concentration of oil dispersant causes a marked reduction in the ability of the mussels to survive freezing at $-10^{\circ} \mathrm{C}$. Thus. exposure to the dispersant clearly reduces the freezing tolerance of the animals.

Freezing also causes the alterations in transmembrane ionic distributions observed following exposures to increasing concentrations of dispersant, to become more pronounced. This may indicate that the effects of freezing are qualitatively the same as those caused by exposure to the dispersant alone. but brought into more extreme conditions. Consequently, the present results do not indicate that the oil dispersant reduces the freezing tolerance of the animals by affecting the special cold-hardening mechanisms of the animals. This conclusion is supported by the fact that all changes in solute concentrations became more extreme when they were calculated for injured animals separately, without regard to whether the injured animals had been frozen or only exposed to the dispersant.

As pointed out by Aarset \& Zachariassen (1982), freezing is likely to potentiate the effect of environmental pollutants by concentrating them in the fluid fraction of the frozen body fluids. This effect allows the pollutants to act in injurious concentrations inside a frozen animal, although they occur in harmless levels in the environment and in unfrozen specimens. A mechanism of this kind might be the basis of the freezing induced injuries observed in $M$. edulis mussels in the present study.

Following freezing the animals showed an increasing recovery with time. Animals frozen in high concentrations of dispersant needed more thawing-time to recover than animals frozen in low dispersant concentrations. This implies that the injury concept is not easily defined, and that the time parameter has to be taken into consideration in a manner which depends on the dispersant concentration used.

When dispersant is used to clean oil from beaches, animals may be exposed to undiluted dispersant and left in air until either the incoming tide or the use of water hoses wash off the contaminants. Consequently, one should be careful when drawing firm conclusions about the applicability of the present results in situations involving use of dispersant against oil spills. Before such conclusions can be drawn, more studies are needed, both in the field where oil dispersants are used in combination with oil and in the laboratory.

Acknowledgement. - This study has been sponsored by the Norwegian Marine Pollution Research and Monitoring Programme. The authors thank Mrs. A. Lohrmann for technical assistance.

\section{References}

Aarset. A. V. \& Zachariassen, K. E. 1982: Effects of oil pollution on the freezing tolerance and solute concentrations of the blue mussel (Mytilus edulis L.). Mar. Biol. 72, 45-51. 
Bayne, B. L., Widdows, J. \& Thompson, R. I. 1976: Physiology 11. Pp. 207-260 in Bayne, B. L. (ed.): Marine Mussels, their Ecology and Physiology. Cambridge University Press, Cambridge.

Crapp, G. P. 1971: Laboratory experiments with emulsifiers. In Cowell. E. B. (ed.): The Ecological Effects of Oil Pollution on Littoral Communities.

Finney, D. J. 1971: Probit Analysis. Cambridge University Press, Cambridge.

Fossato, V. U. \& Canzonier, W. J. 1976: Hydrocarbon uptake and loss by the mussel Mytilus edulis. Mar. Biol. 36. 243250.

George, M. 1961: Oil pollution of marine organisms. Nature (London) 192, 1209.

Kanwisher, J. W. 1955: Freezing in intertidal animals. Biol. Bull. 109, 56-63.

Lange, R. 1963: The osmotic function of amino acids and taurine in the mussel Mytilus edulis. Comp. Biochem. Physiol. 10, 173-179.

Lee, R. F., Sauerheber, R. \& Benson, A. A. 1972: Petroleum hydrocarbons: uptake and discharge by the marine mussel Mytilus edulis. Science, N.Y. 177, 344-346.

Little, J. R. 1964: Determination of water and electrolytes in tissue slices. Analyt. Biochem. 7. 87-95.

Lutz, P. T. 1972: Extracellular spaces and composition of various tissues of perch. Comp. Biochem. Physiol. 41A, 77-88.
Moore, S. \& Stein, W. H. 1948: Photometric ninhydrin method for use in the chromatography of amino acids. J. Biol. Chem. $176,367-388$.

Moore, S. \& Stein, W. H. 1954: A modified ninhydrin reagent for the photometric determination of amino acids and related compounds. J. Biol. Chem. 211, 907-913.

Nelson-Smith, A. 1968: The effects of oil pollution and emulsifier cleansing on shore life in south-west Britain. J. Appl. Ecol. 5, 97-107.

Odum, H. T., Copeland, B. J. \& Mahan, E. A. 1974: Coastal Ecological Systems of the United States. Vol. III. Conserv. Found., Washington, D.C.

Pequignat, E. 1973: A kinetic and autoradiographic study of the direct assimilation of amino acids and glucose by organs of the mussel Mytilus edulis. Mar. Biol. 19, 227-244.

Simpson, A. C. 1968: Oil, emulsifier and commercial shellfish. Pp. 1-91 in Carthy, J. D. \& Arthur, D. R. (eds.): The Biological Effects of Oil Pollution on Littoral Communities. Field Studies Council.

Swedmark, M. B., Emanuelsson, E. \& Granmo, Å. 1971: Biological effects of surface active agents on marine animals. Mar. Biol. 9, 183-201.

Whittam, R. 1955: A conventional micromethod for the estimation of tissue chloride. J. Physiol. 120, 65 .

Williams, R. J. 1970: Freezing tolerance in Mytilus edulis. Comp. Biochem. Physiol. 35, 145-161. 
